\title{
Portfolio Insurance Using Traded Options
}

\author{
Carlos Machado-Santos
}

\section{RESUMO}

A literatura relativa ao uso institucional de opções indica que o principal objectivo destes activos é dar aos investidores a oportunidade para criar distribuições de retorno previamente inatingíveis, considerando que as opções fornecem os meios para manipular o retorno das carteiras. Neste contexto, o presente estudo tem por objectivo analisar os retornos gerados por carteiras de acções cobertas com opções. Dado que a cobertura dinâmica é dispendiosa, utilizamos um esquema de cobertura discreto, em que as posições são revistas quando a ratio de cobertura diária varia para além de um valor específico. Os resultados obtidos por este tipo de cobertura indicam que um pequeno aumento do desvio padrão parece ser largamente compensado por retornos médios mais elevados. De facto, tais estratégias parecem ser largamente influenciadas pelos movimentos de preço das acções subjacentes, que requerem ajustes mais freqüentes (escassos) em períodos de volatilidade elevada (reduzida). Neste sentido, estas estratégias discretas parecem mais consistentes e significativas que os arbitrários intervalos regulares de tempo largamente apresentados e debatidos na literatura.

Palavras-chaves: opções; cobertura de risco; protecção de carteiras.

\begin{abstract}
Literature concerning the institutional use of options indicates that the main purpose of option trading is to provide investors with the opportunity to create return distributions previously unavailable, considering that options provide the means to manipulate portfolio returns. In such a context, this study intends to analyse the returns of insured portfolios generated by hedging strategies on underlying stock portfolios. Because dynamic hedging is too expensive, we have hedged the stock positions discretely, in a way that the positions were revised only when the daily hedge ratio has changed more than a specific amount. The results, provided by these hedging schemes, indicate that a small rise of the standard deviation seems to be largely compensated with the higher average returns. In fact, such strategies seem to be highly influenced by the price movements of underlying stocks, requiring more frequent (sparse) adjustments in periods of high (low) volatility. Thus, discrete hedging strategies seem more accurate and meaningful than the arbitrary regular intervals largely presented and discussed in literature.
\end{abstract}

Key words: options; hedging; portfolio insurance. 


\section{INTRODUCTION}

The literature concerning the institutional use of options implies two primary motivations: risk reduction and the expansion of investment opportunities. Prior work has provided empirical evidence of the achievement of these benefits. For example, Merton, Scholes and Gladestein $(1978,1982)$ noted that the existence of options significantly expands the market dimension, through a study where they analysed the risk and return of alternative call and put option portfolio investment strategies. Bookstaber and Clarke $(1981,1983)$ showed that the growth of options markets and its use by investors overcome the limitations of the stock portfolios in meeting the investment objectives. As they stated, "it is only by going beyond the confines of the stock portfolio that the flexibility required to meet more detailed investment objectives can be realised" (Bookstaber and Clarke, 1983, p. 4). In this way, options provide the means to manipulate portfolio returns and, therefore, can be used for several purposes, specially protecting market exposure.

In this context, this study intends to analyse the returns of insured portfolios, generated by hedging strategies. Consequently, our attention is devoted to the implementation of delta hedging strategies, using listed options, on long positions in constructed underlying stock portfolios.

\section{Review of Hedging Strategies}

The application of traditional insurance theory is discussed in Leland (1980), where the author develops two conditions that imply a preference for the protective put. The first condition is that the investor who shows risk tolerance tends to choose a spot portfolio with higher risk than the average portfolio and to purchase insurance. The seller of the insurance would hold a spot position that contains less market risk. The second condition is that the investor hold more optimistic expectations than the average. In order to trade on these beliefs, but still maintain acceptable risk levels, portfolio insurance will be purchased. Benninga and Blume (1985) illustrate that the insurance strategies can, in general, be optimal only for utility maximisers whose utility functions display non-constant coefficients of relative risk aversion. Brooks and Levy (1993) applied stochastic dominance and expected utility maximisation methods on the S\&P 500 index and its various option 
combination strategies. They notice that only those investors with extreme risk aversion may see fit to use portfolio insurance.

In this way, delta based strategies, which rely on dynamic hedging through the Black-Scholes Option Pricing Model (B\&S), has been adopted by most academics and practitioners for hedging purposes. Black and Scholes (1973) demonstrated that a risk free portfolio can be made by adding a short (long) position on a call option to a long (short) position on the underlying asset in a certain proportion, which is given by the B\&S formula. Since then, a vast literature addressed the effects of options positions in a stock portfolio context. While, for example, Ross (1976), Breeden and Litzenberger (1978) and Arditti and John (1980) have demonstrated the potential of option portfolio strategies in moulding the return distributions, other studies provided an empirical view of just what effect a particular stock option hedging strategy (e.g., covered call and/or protective put) will have in altering risk-return patterns.

One of the main studies in this area is that of Merton, Scholes and Gladstein (1978), who formed hedging strategies using the stocks for which there were options listed. The results for the covered call indicate that the stock option positions provided consistently lower returns than the stocks alone when stocks were bullish, but also lower losses for decreases in stock prices. Also, this strategy displayed lower variance than the stock spot price. Later, Merton, Scholes and Gladstein (1982) examined uncovered put writing and the protective put. Their findings were that higher exercise prices tend to generate greater risk, and that the protective put resulted in slightly lower returns than the stock-only positions, but also provided much lower risk. The main contribution of these studies was to provide evidence of the impact on realised returns and the risk-return characteristics of stock portfolios hedged with covered calls and protective puts strategies. However, they hedged only a given percentage ${ }^{(1)}$ of the underlying stock portfolio, not through the exact delta hedging concept that results from the B\&S, which assumes that delta hedge positions are risk free when rebalanced continuously.

In this way, more recently, researchers have shown the benefits of delta hedging strategies (with listed options) in a wide range of applications. For example, Alderson and Zivney (1989) examined the effectiveness of delta hedging on the maintenance of covered index option positions. Generally, the strategy exhibited lower levels of risk without significant losses in returns. Other major studies in this area are the one of Becker and Lemgruber (1989), where, through efficiency tests on the Brazilian options market (based on the Black-Scholes model), some effectiveness was detected. Later, Lemgruber, Becker and Felício (1991) applied portfolio insurance strategies, using synthetic put options, to the Brazilian gold market. The results, as broadly presented in the literature, seem to support the efficiency of the strategy. 
Kawaller (1993) presents arguments in favour of delta hedging strategies using options, referring to the idea of insurance to protect against adversity alone, without foregoing the beneficial market effects. This result is exactly what follows from an option hedge. Strong and Dickison (1994) used call options on the S\&P 100 index over the period of 1984 to 1988 , to study the impact of the volatility estimator on delta hedging strategies. Hancock and Weise (1994) provide empirical evidence on the effectiveness of derivatives to hedge a long position in the S\&P 500 stock index over the period of 1987 to 1989. Among other derivative strategies, they studied the covered call and protective put using the B\&S delta hedging with listed options.

Although delta is the most discussed and used method for hedging purposes, it has been argued that delta hedging may not eliminate all risk (Neuberger, 1994). Some authors suggest more sophisticated strategies for improving hedging effectiveness. However, Clewlow et al. (1993) studied the effectiveness of various methods of hedging (delta, delta+gamma ${ }^{(2)}$ and delta+veja ${ }^{(3)}$ ) of stock index options, analysing errors decomposition. No real improvement was found in delta+gamma or delta+vega hedging, even though delta+gamma hedging seemed to be slightly more effective. Also, Duque and Paxson (1994), using a sample of equity options, tested whether complex hedging is more effective than simple delta hedging and found no evidence to support such a hypothesis.

\section{Methodology}

Among all theories in finance, the option pricing model derived by Black and Scholes (1973) has perhaps had the biggest impact on the real world of securities trading and has been widely adopted for hedging purposes. According to this model, the theoretical value of a European call option may be expressed as follows:

$$
c=S N\left(d_{1}\right)-X e^{-r(T-t)} N\left(d_{2}\right)
$$

where:

$$
d_{1}=\frac{\ln \left(\frac{S}{X}\right)+\left(r+\frac{\sigma^{2}}{2}\right)(T-t)}{\sigma \sqrt{T-t}} ; d_{2}=d_{1}-\sigma \sqrt{T-t}
$$

and, $\mathrm{S}$ is the underlying market asset price; $\mathrm{X}$ is the exercise price; $\mathrm{r}$ is the continuously compounded risk free interest rate ${ }^{(4)} ; \mathrm{T}-\mathrm{t}$ is the time to expiration; $\sigma$ 
is the volatility of the asset price return; $\mathrm{N}($.$) is the cumulative probability$ distribution function for a standardised normal variable. Black and Scholes (1973) developed their model to price call options only. However, applying the put-call parity $^{(5)}$, the theoretical value for a European put option gives:

$$
\mathrm{p}=\mathrm{S}\left[\mathrm{N}\left(\mathrm{d}_{1}\right)-1\right]+\mathrm{Xe}^{-\mathrm{r} T-\mathrm{T}}\left[1-\mathrm{N}\left(\mathrm{d}_{2}\right)\right]
$$

On the other hand, Black and Scholes (1973) showed that, adding a short (long) position on a call option (the derivative security) with a long (short) position on the stock (the underlying security) in a proportion given by delta - $\mathrm{N}\left(\mathrm{d}_{1}\right)$ - results in a portfolio which should earn exactly the risk free interest rate (r), since its risk is nil. Thus, for a portfolio that combines call options (c) and the underlying stock (S):

$$
\Pi=Q_{c} c+Q_{s} S
$$

where $\Pi$ is the portfolio value and $\mathrm{Q}_{\mathrm{c}}$ and $\mathrm{Q}_{\mathrm{s}}$ are, respectively, the proportions invested in the call option and in the underlying stock. For the short time period, $\Delta t$ changes in value of $\mathrm{c}$ and $\mathrm{S}$ results in a discrete process $^{(6)}$, where the expected drift rate per unit of time $(\mu)$ is now $r$. In such a context, changes in the portfolio value are given by:

$$
\Delta \Pi=\left(Q_{c} c+Q_{S} S\right)+\Delta t+\left(Q_{c} \wedge\left(d_{1}\right)+Q_{s}\right) \sigma S \Delta z
$$

Equivalently:

$$
\Delta \Pi=\Pi r \Delta t+\left(\mathrm{Q}_{\mathrm{c}} \mathrm{N}\left(\mathrm{d}_{1}\right)+\mathrm{Q}_{\mathrm{S}}\right) \sigma \mathrm{S} \Delta z
$$

Since $\Delta \Pi$ should be equal to $\Pi r \Delta t$, i.e., should earn exactly the risk free rate, it gives:

$$
Q_{c} N\left(d_{1}\right)+Q_{s}=0
$$

which implies that:

$$
Q_{r}=-\frac{1}{N\left(d_{1}\right)} Q_{s} \text { or } Q_{s}=-N\left(d_{1}\right) Q_{s}
$$

Thus, from Equation [7] it follows that a long call option position can be delta hedged with a short position in $\mathrm{N}\left(\mathrm{d}_{1}\right)$ shares of the underlying stock. Similarly, a long position in the stock can be delta hedged with a short position in $1 / \mathrm{N}\left(\mathrm{d}_{1}\right)$ call options on that stock. Such a hedge is said to be delta neutral and requires option 
contracts in a proportion reciprocal to $\mathrm{N}\left(\mathrm{d}_{1}\right)$. This is the case of the covered call (stock plus a short call). On the other hand, for a portfolio that combines put options (p) and the underlying stock $(\mathrm{S})$ :

$$
\Pi=Q_{p} p+Q_{S} S
$$

where $Q_{p}$ is the proportion invested in the put option and $Q_{s}$ is as previously defined. In a process analogous to the one analysed for the call options, changes in the portfolio value are given by:

$$
\left.\Delta \Pi=\left(\mathrm{Q}_{\mathrm{p}} \mathrm{p}+\mathrm{Q}_{\mathrm{s}} \mathrm{S}\right) \mathrm{r} \Delta t+\mathrm{Q}_{\mathrm{p}}\left(\mathrm{N}\left(\mathrm{d}_{1}\right)-1\right)+\mathrm{Q}_{\mathrm{s}}\right\rfloor \sigma \mathrm{S} \Delta z
$$

Equivalently:

$$
\Delta \Pi=\Pi r \Delta t+\left\lfloor\mathrm{Q}_{\mathrm{p}}\left(\mathrm{N}\left(\mathrm{d}_{1}\right)-1\right)+\mathrm{Q}_{\mathrm{s}}\right\rfloor \sigma \mathrm{S} \Delta z
$$

Again, since $\Delta \Pi$ should be equal to $\Pi r \Delta t$, i.e., should earn exactly the risk free interest rate, it gives:

$$
\mathrm{Q}_{\mathrm{p}}\left(\mathrm{N}\left(\mathrm{d}_{1}\right)-1\right)+\mathrm{Q}_{\mathrm{s}}=0
$$

which implies that:

$$
Q_{p}=-\frac{1}{N\left(d_{1}\right)-1} Q_{S} \quad \text { or } \quad Q_{S}=-\left(N\left(d_{1}\right)-1\right) Q_{p}
$$

From the above equations it follows that a long put option position should be delta hedged with a long position in $\mathrm{N}\left(\mathrm{d}_{1}\right)-1$ shares of the underlying stock. Similarly, a long position in the stock can be delta hedged with a long position in $1 /\left[\mathrm{N}\left(\mathrm{d}_{1}\right)-1\right]$ put options on that stock. This is the case of the protective put (stock plus a long put).

\section{Data Description}

The data collected for this study consists on traded equity options quoted on the London International Financial Futures and Options Exchange (LIFFE) and stocks from companies quoted on the London International Stock Exchange. We have collected the equity options bid and ask closing prices, as well as the underlying stock closing prices (and the dividends paid), from a total of $82^{(7)}$ of those securities available on October 96. This upper period limit was imposed by the time we 
collect the data (nearly November 96). In order to decide what time period should be covered and, therefore, the lower limit of our sample period, only securities (stocks and options) that have been traded, at least, over the last two years (October 94 to October 96) were selected to the sample ${ }^{(8)}$. After, some firms were removed because they: (1) began to trade at a latter stage; (2) were in the process of being delisted around the end-of-sample period; or (3) were subjected to take-over activities during the time sample period. Next, we separate the remaining stocks into three main groups, according to their option expiring dates ${ }^{(9)}$. Again, we have removed from the sample firms that were reallocated to a new expire cycle during the two years period. After this, the following stocks were kept from the original data sample: 26 Stocks (January Cycle), 20 Stocks (February Cycle) and 8 Stocks (March Cycle). Finally, we have chosen the January Cycle because it has the highest number of stocks within the same group, and their options expire in October, being coincident with the limits of our original data sample period (see Appendix 1).

On the other hand, given that the composition and strategies of hedged portfolios are not available in the market, such data was simulated. In this context, we have constructed 5 underlying stock portfolios and implemented 30 different option delta hedge strategies on such portfolios. Thus, the final data sample for this study includes daily returns of each stock-option strategy from 150 different portfolios simulated.

\section{The Underlying Stock Portfolios}

To the definition of the stock portfolios that underlie the option strategies, we first selected three (out of 20) efficiently diversified portfolios using the assumptions of the Markowitz (1952) mean variance efficient frontier model ${ }^{(10)}$. Assuming no budget constraints, that equities are infinitely divisible, there is no riskless lending and borrowing and short sales are not allowed, the efficient set can be calculated by minimising the risk for any level of expected return as follows:

Minimise:

$$
\sigma_{P}=\sqrt{\sum_{i=1}^{N} X_{i}^{2} \sigma_{i}^{2}+\sum_{i=1}^{N} \sum_{\substack{i=1 \\ j \neq i}}^{N} X_{i} X_{j} \sigma_{i j}}
$$

Subject to:

$$
\overline{\mathrm{R}}_{\mathrm{p}}=\sum_{\mathrm{i}=1}^{\mathrm{N}} \mathrm{X}_{\mathrm{i}} \overline{\mathrm{R}}_{\mathrm{i}} \quad ; \quad \sum_{\mathrm{i}=1}^{\mathrm{N}} \mathrm{X}_{\mathrm{i}}=1 ; \mathrm{X}_{\mathrm{i}} \geq 0 \text {, all } i
$$

where $\sigma_{p}$ is the total risk (standard deviation) of the portfolio; $\overline{\mathrm{R}}_{\mathrm{p}}$ is the expected return of the portfolio; $\overline{\mathrm{R}}_{\mathrm{i}}$ is the expected return of security $\mathrm{i}$; $\mathrm{X}_{\mathrm{i}}$ is the proportion 
of the portfolio hold in security $i$; $\sigma_{\mathrm{ij}}$ is the covariance of the returns between security $\mathrm{i}$ and $\mathrm{j} ; \mathrm{N}$ is the number of securities in the portfolio. The stock returns (adjusted for dividends) were computed in logarithmic form as follows:

$$
R_{i, t}=\operatorname{Ln}\left(\frac{S_{i, t}+D_{i, t}}{S_{i, t-1}}\right)
$$

where $R_{i, t}$ is the return of security $i$ in period $t ; S_{i, t}$ is the price of security $i$ at the end of period $t ; D_{i, t}$ are the dividends paid by security i during period $t ; S_{i, t-1}$ is the price of security $i$ at the end of period $t-1$. Then, we created an alternative scenario where an equal weighted portfolio was defined from the resulting composition of the previous efficient portfolios as well as a portfolio of randomly selected stocks from the equities available in the main data sample. Once the portfolio holdings were selected, an equal weight have been assigned to each security (see Appendix 1).

\section{The Option Hedging Strategies}

The B\&S model, with the adjustments mentioned earlier, was used for the implementation of hedging strategies. As we saw, for a portfolio that combines call options and the underlying stock, the number of calls to short is given by the hedge ratio $\mathrm{Q}_{\mathrm{C}, \mathrm{t}}=1 / \mathrm{N}\left(\mathrm{d}_{1,1}\right)$. Similarly, for a portfolio that combines put options and the underlying stock, the number of puts to purchase is given by $\left.\mathrm{Q}_{\mathrm{P}, \mathrm{t}}=1 / 1-\mathrm{N}\left(\mathrm{d}_{1, t}\right)\right\rfloor$. The daily return on the call hedged stock $-\mathrm{R}_{\mathrm{C}, \mathrm{t}}-$ and the return on the put hedged stock $-\mathrm{R}_{\mathrm{P}, \mathrm{t}}$ - are defined as follows (Hancock and Weise, 1994):

$$
\begin{aligned}
& \mathrm{R}_{\mathrm{C}, \mathrm{t}}=\mathrm{R}_{\mathrm{s}, \mathrm{t}}-\left(\mathrm{Q}_{\mathrm{C}, \mathrm{t}-1} \times \mathrm{R}_{\mathrm{c}, \mathrm{t}}\right) \\
& \mathrm{R}_{\mathrm{P}, \mathrm{t}}=\mathrm{R}_{\mathrm{s}, \mathrm{t}}+\left(\mathrm{Q}_{\mathrm{P}, \mathrm{t}-1} \times \mathrm{R}_{\mathrm{p}, \mathrm{t}}\right)
\end{aligned}
$$

where $R_{C, t}$ and $R_{P, t}$ are the daily returns of the call and put option, respectively, $\mathrm{R}_{\mathrm{s}, \mathrm{t}}$ is the daily returns of the underlying stock, and other variables are as previously defined. For the implementing of the option hedging strategies, we have considered only a long position in the spot. This long position is taken for each stock in the 5 portfolios previously constructed, with fully covered positions. Three different strategies were created for both covered call and protective put positions, that differ only with the exercise price/stock price (X/S) relationship. Thus, for call options we have: $\mathrm{X} / \mathrm{S}=0.9,1.0$ and 1.1 (IN, AT and OUT-of-the-money). Because of the period between option exercise dates (within the same cycle) all the call options written have 3 month maturities and, within each portfolio, all options written had the same exercise price/stock price ratio. Similarly, for put options 
we have: $\mathrm{X} / \mathrm{S}=1.1,1.0$ and 0.9 (IN, AT and OUT-of-the-money). Within each portfolio all put options bought have the same exercise price/stock price ratio. In addition, each period, the exercise price of both call and put options is changed in order to match the requirement of being closest ${ }^{(11)}$ IN, AT or OUT-of-the-money.

Assuming that no transaction costs (TC) are charged during readjustments, the positions were opened and closed daily (the time interval was restricted by the data collected). The returns were also computed daily. The option premiums considered are the average of daily closing quoted prices - (bid+ask)/2. When TC (bid-ask spread) ${ }^{(12)}$ are considered the positions would be opened by selling (buying) a certain quantity of calls (puts). The positions are also readjusted daily but, contrary to the delta strategies implemented earlier when avoiding transaction costs, only the portion necessary to readjust is exposed to the erosion of the spread, i.e., we should buy or sell option contracts only in the amount given by the difference between the delta hedge ratio necessary each day and the positions previously open (see Appendix 2 for a list of the strategies selected).

\section{EMPIRICAL EvidenCE}

\section{The Realised Returns}

Assuming that no transaction costs are charged during readjustments in the positions, we began to delta hedge using the AT, IN and OUT-of-the-money strategies above mentioned. Both positions were opened and closed daily and the returns were also computed daily. Table 1 below presents the average returns and other descriptive statistics from the call option strategies among the 5 hedged portfolios, compared with the stocks-only positions.

Table 1: Average Returns from CALL Option Delta Hedging Strategies

Portfolios 1 to 5 - Without Transaction Cos

\begin{tabular}{l|r|r|r|r}
\hline & Stocks Only & C-IN & C-AT & ( \\
\hline Mean & $0.0791 \%$ & $0.0221 \%$ & $0.0254 \%$ & \\
S.Dev. & $0.6665 \%$ & $0.1207 \%$ & $0.1988 \%$ & \\
Kurtosis & 0.3804 & 4.3954 & 5.0526 & \\
Skewness & -0.0843 & -0.1692 & -0.4832 & \\
N.Obs. & 485 & 485 & 485 & \\
\hline
\end{tabular}


The above results show a considerable reduction in the average standard deviation of the returns (among the 5 portfolios) resulting from the call delta hedging strategies, compared with the stocks-only positions. In fact, we can observe a sharp fall in the standard deviation in all the strategies, specially for the IN-themoney (C-IN) that provides the lowest level of risk $(0.1207 \%)$ compared with the AT (C-AT) and OUT-of-the-money (C-OUT) strategies which exhibit $0.1988 \%$ and $0.2588 \%$ respectively. It also appears that the reduction of the average returns (with values between $0.0221 \%$ and $0.0285 \%$ ) is less significant than the reduction in risk.

Analysing the results of the individual portfolios (see Appendix 3) we find a very similar pattern of returns and risk of each of the five (efficient and not efficient) portfolios. The kurtosis and skewness statistics seem not to be far from the normal distribution values, except the average kurtosis of the OUT-ofthe-money strategies (C-OUT) for the five portfolios which is closed to 0.91 instead of the normalised value of 3.0.

The average returns from the put option strategies among the 5 hedged portfolios compared with the stocks-only positions are shown in Table 2 below.

\section{Table 2: Average Returns from PUT Option Delta Hedging Strategies}

Portfolios 1 to 5 - Without Transaction Costs

\begin{tabular}{l|r|r|r|r}
\hline & Stocks Only & P-IN & P-AT & I \\
\hline Mean & $0.0791 \%$ & $0.0182 \%$ & $0.0207 \%$ & । \\
S.Dev. & $0.6665 \%$ & $0.1416 \%$ & $0.2143 \%$ & । \\
Kurtosis & 0.3804 & 4.2223 & 3.6501 & \\
Skewness & -0.0843 & 0.8168 & 0.4240 & \\
N.Obs. & 485 & 485 & 485 & \\
\hline
\end{tabular}

The above results also show a reduction in the average standard deviation of the returns (among the 5 portfolios) resulting from the put delta hedging strategies, compared with the stocks-only positions. Again, a sharp fall is observed in the standard deviation of all the strategies, specially for the IN-the-money (P-IN) that provides a much lower level of risk $(0.1416 \%)$ compared with the AT (P-AT) and OUT-of-the-money (P-OUT) strategies which exhibit $0.2143 \%$ and $0.2902 \%$ respectively.

From the individual portfolios (see Appendix 3) we also find a very similar pattern of returns and risk for portfolios 1 to 5. The kurtosis and skewness estimates are similar, in absolute value, to the call strategies, with the average 
kurtosis of the OUT-of-the-money strategies (P-OUT) for the five portfolios presenting the smallest estimate in the whole sample. However, using put options, the sign of the skewness is positive (the returns distribution is slightly skewed), instead of the negative skewness values achieved with the use of call options.

Contrary to what is theoretically expected, it seems not to be indifferent to chose IN, AT or OUT-of-the-money strategies, in terms of both the level of risk and return. Given that the daily average for the 3 -month TB in the period studied was $0.0167 \%$, this should be, on average, the return achieved whatever the strategy used. That is, the target return for call and put hedged portfolios should be simply the daily risk free rate.

However, this results are in accordance with some empirical studies such as, for example, Duque and Paxson (1994), which found different average returns depending on the option's moneyness. They have also achieved positive excess returns when avoiding transaction costs. The previous results also demonstrate that a hedged portfolio may not display returns as large as a comparable unhedged portfolio (stocks-only). This cost can be viewed as the return forgone as a result of adopting these risk limiting strategies.

When considering the transaction costs, the positions were also readjusted daily but, contrary to the delta strategies implemented earlier when avoiding transaction costs, only the portion necessary to readjust was exposed to the erosion of the spread, i.e., we should buy or sell option contracts only in the amount given by the difference between the delta hedge ratio necessary each day and the positions previously open. All the remaining procedures were unchanged.

Table 3 below presents the average returns as well as other descriptive statistics from the call (C-...-TC) and put (P-...-TC) option hedging strategies, including transaction costs, among the 5 hedged portfolios.

\section{Table 3: Average Returns from CALL and PUT Option Delta Hedging Strategies}

Portfolios 1 to 5 - Including Transaction Costs

\begin{tabular}{l|r|r|r|r}
\hline & C-IN-TC & C-AT-TC & C-OUT-TC & P-IN-TC \\
\hline Mean & $-0.0100 \%$ & $-0.0311 \%$ & $-0.0349 \%$ & $-0.0086 \%$ \\
S.Dev. & $0.1325 \%$ & $0.2183 \%$ & $0.2768 \%$ & $0.1647 \%$ \\
Kuntosis & 3.3150 & 4.1076 & 1.1071 & 4.1204 \\
Skewness & -0.1494 & -0.4436 & -0.2256 & 0.3106 \\
N.Obs. & 485 & 485 & 485 & $48 \%$ \\
\hline
\end{tabular}


The above results indicate that all strategies perform worse as compared with those previously shown in Tables 1 and 2. In fact, considerable reduction is shown in the average returns (among the 5 portfolios) compared with the same strategies when transaction costs were not considered. However, this decrease was not followed by the standard deviation, which displays values which are only slightly higher than those in Tables 1 and 2.

The kurtosis and skewness estimates are also similar, with the average kurtosis of the OUT-of-the-money strategies (...-OUT-TC) presenting the smallest value. Again, the sign of the skewness is negative for calls (the return distributions are slightly skewed to the right) and positive for puts (the return distributions are slightly skewed to the left).

From the individual portfolios (see Appendix 4) we also find a very similar pattern of returns and risk for portfolios 1 to 5, although, in general, the IN-themoney (...-IN-TC) strategies provide a lower level of risk compared with the AT (...-AT-TC) and OUT-of-the-money (...-OUT-TC) strategies for both call and put options. Such results show that the dynamic hedging (to all the portfolios in the sample) could be very expensive and remove any potential gain from the portfolio protection. Therefore, investors will be motivated to rebalance their hedged positions using the longest (and least expensive) rebalancing interval for which they believe their delta hedged positions will remain almost risk free.

In order to reduce costs, delta hedging at discrete intervals has been suggested ${ }^{(13)}$. Gemmill (1993) showed that the rebalancing frequency is a function of the loss from hedging errors and the transaction costs. In this way, rebalancing should be done whenever the stock price has moved by some predetermined amount. Nevertheless, besides providing for some amount of risk, such intervals are somewhat arbitrary.

Etzioni (1986) showed that adjusting only when the hedge ratio moves by more than some amount, is the best way to minimise transaction costs and replication errors, i.e., changes in the hedge ratio requires that (1) for periods of more volatility, the costs from rebalancing in more frequent intervals may be compensated with less risk involved in the hedged position and (2) for periods of low market volatility (there are less risks involved) rebalancing in more discrete intervals may be worth. In this context, we have tried a different hedging scheme where the option positions should be readjusted only when the daily delta ratio has changed more or equal to $5 \%{ }^{(14)}(\mathrm{D} 5), 10 \%$ (D10) or $15 \%$ (D15). All the remaining procedures were kept identical. 
Table 4 below present the average returns (among the 5 portfolios) from the call and put option hedging strategies, including transaction costs and considering these discrete rebalancing intervals.

\section{Table 4: Average Returns from CALL and PUT Option Delta Hedging Strategies}

Portfolios 1 to 5 - Discrete Rebalancing Intervals

\begin{tabular}{|c|c|c|c|c|c|c|}
\hline & \multicolumn{3}{|c|}{ A: IN-the-Money Strategies } & \multicolumn{3}{|c|}{ B: AT-the-Money Strategies } \\
\hline Calls & C-IN-D5 & C-IN-D10 & C-IN-D 15 & C-AT-D5 & C-AT-D 10 & C-AT-D15 \\
\hline Mern & $-0.0042 \%$ & $0.0008 \%$ & $0.0067 \%$ & $-0.0150 \%$ & $0.0001 \%$ & $0.0107 \%$ \\
\hline S.Dev. & $0.1400 \%$ & $0.1479 \%$ & $0.1599 \%$ & $0.2331 \%$ & $0.2533 \%$ & $0.2730 \%$ \\
\hline Kurtosis & 3.1041 & 2.7931 & 2.2454 & 4.4204 & 42639 & 4.7826 \\
\hline Skewness & -0.1678 & -0.1294 & -0.1338 & -0.6691 & -0.7052 & -0.7569 \\
\hline N.Obs. & 485 & 485 & 485 & 485 & 485 & 485 \\
\hline Puts & P-IN-D5 & P-IN-D10 & P-IN-D 15 & P-AT-D5 & P-AT-D10 & P-AT-D15 \\
\hline Mean & $-0.0040 \%$ & $-0.0003 \%$ & $0.0038 \%$ & $-0.0017 \%$ & $0.0019 \%$ & $0.0092 \%$ \\
\hline S.Dev: & $0.1711 \%$ & $0.1800 \%$ & $0.1924 \%$ & $0.2971 \%$ & $0.3109 \%$ & $0.3221 \%$ \\
\hline Kutosis & 3.6002 & 3.4349 & 3.5781 & 3.6770 & 3.4162 & 3.4817 \\
\hline Sleewhess & 0.3862 & 0.5027 & 0.6798 & 0.5098 & 0.5843 & 0.5700 \\
\hline N.Obs. & 485 & 485 & 485 & 485 & 485 & 485 \\
\hline
\end{tabular}

The results seem to support the use of the discrete hedging scheme, with the average returns (among the 5 portfolios) increasing as the rebalancing is made at less frequent intervals. That is, compared with the daily dynamic hedging, it appears to be worth readjusting the positions only when delta changes by more than a certain amount. In fact, the small rise in the standard deviation seems to be largely compensated by the gains in the returns as we move from the more frequent (D5) to the less frequent (D15) intervals. The D15 strategies especially achieved much higher average returns than all other hedging strategies considering transaction costs, for both call and put options. From the individual portfolios (see Appendixes 5 and 6) we also find a very similar pattern of returns and risk for the D5, D10 and D15 strategies among portfolios 1 to 5. The kurtosis and skewness estimates are similar, in absolute value, to the daily dynamic hedging (with and without transaction costs). Again, the sign of the skewness is slightly negative to all call option strategies, while the put option strategies present slightly positive skewness statistics.

In this context, the previous results show that the hedged portfolios do not display returns as large as a comparable unhedged (stocks-only) portfolio. However, when transaction costs are considered, the return forgone as a result of hedging is closely related to the rebalancing frequency, i.e., a small fall in the 
portfolios protection seems to be compensated with a larger rise in the returns when hedging in discrete intervals is used.

\section{Comparison between the Strategies}

For a detailed analysis of the results, we tested for significant differences between the returns of the strategies, as well as verify whether the mean returns of those strategies were significantly different when applied to differentially constructed underlying stock portfolios. The experiments were formulated as follows:

Example 1 - Is the mean return of the strategies significantly different from each other? Given that the strategies were implemented according to different levels of TC for the 6 moneyness groups ${ }^{(15)}$, the objective here is to test for significant differences between individual strategies, as well as for differences within each moneyness group.

Example 2 - Is the mean performance significantly different between moneyness groups? This experiment is formulated to test whether (1) the mean performance of each moneyness group is significantly different from other groups, and (2) the mean performance of each class of strategies is significantly different from other classes. In other words, is it indifferent to use AT, IN or OUT-of-themoney options for delta hedging purposes?

Example 3 - Is the mean performance significantly different between portfolios P1 to P5? The purpose here is to test whether the mean performance of the delta option strategies is significantly different when applied on differently constructed underlying stock portfolios.

On the other hand, for the experiments, we carried out the parametric F-test for analysis of variance and the non-parametric Kruskal-Wallis rank test. Although each tests for different mean values among various populations, the primary difference is the assumption concerning the nature of the distributions for the test variable. Therefore, because of their complementary nature, the use of the two statistics seemed appropriate. The F-test for K population means is used to test the null hypothesis that the $\mathrm{K}$ samples came from $\mathrm{K}$ populations with the same mean. This is a parametric test, which assumes that the populations are normally distributed and have equal variances. It also assumes that the samples are independent from each other (Kanji, 1995).

The Kruskal-Wallis test only assumes similar distributions among the population groups. The null hypothesis states that all K population distribution functions are identical or, alternatively, the K populations have equal means (Conover, 1980). 
In this way, with Example 1 we started to test for differences among all the strategies, as well as, separately, for option strategies involving only call writing or put buying. The results confirm that highly significant differences do exist. In fact, the null hypothesis of equal mean returns among all strategies, as a whole and, separately, for calls and puts, is clearly rejected for both F and KruskalWallis tests (see Appendix 7, Panel A) at almost any level of significance (p values approach zero). Very similar results are provided by the F and KruskalWallis statistics (see Appendix 7, Panel B) with p values approaching zero, which clearly indicates that is not indifferent to consider, in the same moneyness group, the inclusion of different levels of transaction $\operatorname{costs}^{(16)}$. In fact, those strategies without TC do perform significantly different from the strategies with TC which, in turn, also show significant different performances between dynamic delta hedging strategies and the discrete D5, D10 and D15 delta hedging scheme. Resuming, and from the statistics presented, we can infer that there are significant differences between strategies within each moneyness group.

For the Example 2 we have started to test for differences among all moneyness groups (with calls and puts), as well as, separately, for groups involving only calls or puts. The results, presented in Panel $\mathrm{C}$ of Appendix 7, provide $\mathrm{F}$ and Kruskal-Wallis statistics that refute the null hypothesis of equality between moneyness groups. On the other hand, testing for mean performance differences within classes of strategies (which contains individual strategies from different moneyness groups), we verify that the null hypothesis of equality is clearly rejected (see Appendix 7, Panel D, Part 1). Running the same tests for mean differences within classes of strategies that involve, separately, either calls (Panel D, Part 2) or puts (Part 3), the results confirm the rejection of the above null hypothesis. Resuming, we can conclude that there are significant mean performance differences for strategies between (or within) moneyness groups and within each class of strategies. Moreover, the same is also true for call versus put strategies, where significant mean performance differences are observed. In this context, it seems to be no indifferent to use call or put strategies as insurance strategies.

For the analysis of Example 3, the $\mathrm{F}$ and Kruskal-Wallis statistics presented in Panel A of Appendix 8 clearly indicate that the null hypothesis of equal mean performance between portfolios cannot be rejected, considering either the average performance of the 30 strategies of each portfolio or the 15 strategies involving, separately, calls and puts. Such results are even more emphasised comparing the portfolios by moneyness groups, where the statistics show, once again, no significant mean performance differences between the 5 portfolios for both call (see Appendix 8, Panel B) and put (Panel C) strategies, either for AT, IN or OUT-ofthe-money. Thus, in this context, we may conclude that, for hedging purposes, the 
way the underlying stock portfolios are simulated (constructed) appears to be indifferent, since no significant mean performance differences were detected.

\section{Concluding Remarks}

The results provided by the simulations show that the delta hedging strategies using both call and put options seem to depend heavily on whether the strategies avoid or incorporate transaction costs and, in a lower degree, on the moneyness of the options. Introducing transaction costs (bid-ask spreads) the results indicate that all strategies perform worse as compared with those ignoring transaction costs. In fact, we verify a large reduction in the average returns. However, this decrease was not followed by the standard deviation, which display identical values to those obtained when transaction costs were not considered. Also, generally, the IN-the-money strategies provide a lower level of risk compared with the AT and OUT-of-the-money strategies for both call and put options. Moreover, the strategies that involve call options seem to achieve, on average, better returns (statistically significant) than those involving put options, even when the discrete hedging scheme is used. Such results are in accordance with most of the studies on this subject, where it has been shown that call options tend to outperform put options hedging strategies.

The results provided by the discrete hedging schemes show that the small rise in the standard deviation seems to be compensated with the gains in the average returns as the strategies move from the more frequent to the less frequent intervals, for both call and put options. For periods of more volatility the positions have to be readjusted more often, involving a higher level of TC and, consequently, lower returns. On the contrary, for periods of less volatility, readjusting is more infrequent and, therefore, the hedging strategies result in better returns. Traditionally, such results were not achieved by discrete hedging in regular intervals of time, where excessive (insufficient) readjusting may occur in periods of low (high) volatility.

To sum up, from the arguments presented above, it seems preferable to use call options for delta hedging purposes, as well as the discrete delta hedging scheme proposed, where the readjusting frequency is closed related to the volatility of the underlying stocks, despite the insurance feature of the put options. On the other hand, the way the portfolios are formed appears not to be important, since no significant statistical differences were found. 


\section{Notes}

${ }^{1}$ For example, Merton, Scholes and Gladestein $(1978,1982)$ used values of $\alpha=0 \%, \alpha=25 \%$, $\alpha=50 \%, \alpha=75 \%$ and $\alpha=100 \%$, where a is the proportion of the underlying stock portfolio to be hedged, for both covered call and protective put.

${ }^{2} \mathrm{Gamma}(\Gamma)$ is the ratio of a change in the option delta for a given change in the underlying stock price. For a call option, $\Gamma_{\mathrm{c}}=\partial \Delta_{\mathrm{c}} / \partial \mathrm{S}$; for a put option, $\Gamma_{\mathrm{p}}=\partial \Delta_{\mathrm{p}} / \partial \mathrm{S}$.

${ }^{3} \mathrm{Vega}(\Lambda)$ is the ratio of a change in the option price to a change in the volatility of the underlying stock price. For a call option, $\Lambda_{\mathrm{c}}=\partial \mathrm{C} / \partial \sigma$; for a put option, $\Lambda_{\mathrm{p}}=\partial \mathrm{P} / \partial \sigma$.

${ }^{4}$ The secondary market Treasury Bills rate (TB) is used as a proxy estimate of the risk free interest rate. However, since TB are expressed as discount rates, the equivalent yield is calculated through the equation $r=d /(1-d(T-t / 365))$, where $r$ is the equivalent yield, $d$ is the quoted TB rate and T$\mathrm{t}$ is the number of days until maturity.

${ }^{5}$ The Put-Call parity states that the value of an European call can be deducted from the value of an European put with the same exercise price and exercise date, and vice versa, according to the

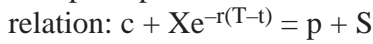

${ }^{6}$ Assuming that the stock price $S$ follows a generalised Wiener process (a continuous time stochastic process, also known as Geometric Brownian Motion. See Shimko (1992), expressed now in discrete terms we have:

$$
\Delta \mathrm{S}=\mu \mathrm{S} \Delta t+\sigma \mathrm{S} \Delta z \quad \text { and } \quad \Delta \mathrm{c}=\left(\frac{\partial \mathrm{c}}{\partial \mathrm{S}} \mu \mathrm{S}+\frac{\partial \mathrm{c}}{\partial \mathrm{t}}+\frac{1}{2} \frac{\partial^{2} \mathrm{c}}{\partial \mathrm{S}^{2}} \sigma^{2} \mathrm{~S}^{2}\right) \Delta t+\frac{\partial \mathrm{c}}{\partial \mathrm{S}} \sigma \mathrm{S} \Delta z
$$

where the $\mu \mathrm{S} \Delta t$ term implies that $\mathrm{S}$ has an expected drift rate of $\mu$ per unit of time; the $\sigma \mathrm{S} \Delta z$ z term can be regarded as the amount of variability added to the path followed by $\mathrm{S}$.

${ }^{7}$ We excluded all the stocks for which there were no traded options. FTSE indexes were also excluded because they do not belong to the population under analysis.

${ }^{8}$ Which guaranties some continuity of the transactions and a fair enough number of observations.

${ }^{9}$ LIFFE provide three cycles for the equity options to expire: the January Cycle - the 3 nearest expire months from Jan./Apr./July/Oct.; the February Cycle - the 3 nearest expire months from Feb./May/Aug./Nov.; and the March Cycle - the 3 nearest expire months from Mar./June/Sept./ Dec.

${ }^{10}$ Besides the great number of studies that employ the Markowitz model, Mueller (1981) was one of the first to use efficient portfolios underlying the implementation of option strategies.

${ }^{11}$ When in absence of exact values for the ratios in each moneyness state and to mitigate any potential bias, the AT-of-the-money contract is defined as the contract which has the smallest absolute different between the exercise price and the price of the underlying stock.

12 In option markets the bid-ask spread is considered the factor with more impact in costs (Berkman, 1991). Also, as stated by Duque and Paxson (1994), no doubt that the bid-ask spread becomes the most important source of costs when hedging strategies are executed.

${ }^{13}$ Such as one week (e.g., Whaley, 1982), two weeks (e.g., Bhattacharya, 1983), one month (e.g., Chiras and Manaster, 1978), and two months (e.g., Leland, 1985). 
14 That is, when $\left(\mathrm{H}_{\mathrm{t}}-\mathrm{H}_{\mathrm{t}-1}\right) / \mathrm{H}_{\mathrm{t}-1} \geq 5 \% . \mathrm{H}_{\mathrm{t}}$ and $\mathrm{H}_{\mathrm{t}-1}$ are, respectively, the delta hedge ratio on day $\mathrm{t}$ and in the previous day $\mathrm{t}-1$.

${ }^{15}$ For the tests, we have organised the data as follows: (1) Moneyness Groups, which are defined for each group of strategies that are included in the same degree of moneyness (e.g., C_AT; C_AT_D15; C_AT_D10; C_AT_D5; C_AT_TC) and (2) Class of Strategies, that represent the strategies of the same kind, but applied in different moneyness groups (e.g., C_AT; C_IN; C_OUT).

${ }^{16}$ Which result from differences in the readjusting frequency.

\section{REFERENCES}

ALDERSON, M. J.;

ZIVNEY, T. L.

Optimal cross-hedge portfolios for hedging stock index options. Journal of Futures Markets, v. 9, n.1, p. 67-75, Feb. 1989.

ARDITTI, F. D.;

JOHN, K.

Spanning the state space with options. Journal of Financial and Quantitative Analysis, v. 15, p. 1-9, 1980.

BECKER, J. L.;

LEMGRUBER, E. F.

Uma análise de estratégias de negociação no mercado brasileiro de opções: evidência das opções de compra mais negociadas durante o plano cruzado. In: BRITO, N. Gestão de investimentos. São Paulo: Editora Atlas, 1989.
BENNINGA, S.;

BLUME, $\mathrm{M}$.

On the optimality of portfolio insurance. Journal of Finance, v. 40, n. 5, p. 1341-1352, Dec. 1985.

BERKMAN, H.

The market spread, limit orders and options. In: $18^{\mathrm{TH}}$ ANNUAL MEETING OF THE EUROPEAN FINANCE ASSOCIATION (1991: Rotterdam). Proceedings... Rotterdam, 1991.

BHATTACHARYA, M.

Transaction data tests of efficiency of the chicago board options exchange. Journal of Financial Economics, v. 12, n. 2, p. 161-185, Aug. 1983.

BLACK, F.;

SCHOLES, M.

The pricing of options and corporate liabilities. Journal of Political Economy, v. 81, n. 3, p. 637-654, May/ June 1973. 
BOOKSTABER, R. M.;

CLARKE, R.

Options can alter portfolio return distributions. Journal of Portfolio Management, v. 7, n. 3, p. 6370, Spring 1981.

Option strategies for institutional investment management. Massachusetts: Addison-Wesley, 1983.

BREEDEN, D. T.;

LITZENBERGER, R. H.

Prices of state-contingent claims implicit in options prices. Journal of Business, v. 51, n. 4, p. 621$651,1978$.

BROOKS, R.;

LEVY, $\mathrm{H}$.

Portfolio insurance: does it pay? Advances in Futures and Options Research, v. 6, p. 329353, 1993.

CHIRAS, D. P.;

MANASTER, S.

The information content of option prices and a test of market efficiency. The Journal of Financial Economics, v. 6, n. 2/3, p. 213234, June/ Sept. 1978.

CLEWLOW, L. et al.

Hedging option position risk: an empirical examination. Working Paper, Financial Options
Research Centre, University of Warwick, 1993.

DUQUE, J. C.;

PAXSON, D. A.

Implied volatility and dynamic hedging. Review of Futures Markets, v. 13, n. 2, p. 381-422, 1994.

ETZIONI, E. S.

Rebalance disciplines for portfolio insurance. Journal of Portfolio Management, v. 13, n. 1, p. 59-62, Spring 1986.

GEMMILL, G.

Options pricing - an international perspective. New York: McGraw-Hill, 1993.

HANCOCK, G.;

WEISE, P. D.

Competing derivative equity instruments: empirical evidence on hedged portfolio performance. Journal of Futures Markets, v. 14, n. 4, p. 421-436, June 1994.

KAWALLER, I. G.

Hedging strategies using derivatives. In: Derivative strategies for managing portfolio risk. [s.l.]: Association for Investment Management and Research Publications, 1993. p. 14-19. 
LELAND, H. E.

Who should buy portfolio insurance? Journal of Finance, v. 35, n. 2, p. 581-596, May 1980.

Option pricing and replication with transaction costs. Journal of Finance, v. 40, n. 5, p. 1283-1301, Dec. 1985.

LEMGRUBER, E. F.;

BECKER, J. L.;

FELÍCIO, R. F.

Seguro dinâmico de portfolio. Revista Brasileira de Economia, [s.n.], out./ dez. 1991.

\section{MARKOWITZ, H. M.}

Portfolio selection. Journal of Finance, v. 8, n. 1, p. 77-91, Mar. 1952.

MERTON, R.;

SCHOLES, M.;

\section{GLADSTEIN, M.}

The returns and risk of alternative call option portfolio investment strategies. Journal of Business, v. 51, n. 2, p. 183-242, 1978.

The returns and risk of alternative put option portfolio investment strategies. Journal of Business, v. 55, n. 1, p. 1-55, 1982.
MUELLER, P. A.

Covered options: an alternative investment strategy. Financial Management, v. 10, n. 3, p. 64-71, Autumn 1981.

NEUBERGER, A.

The log contract. Journal of Portfolio Management, v. 20, n. 2, p. 74-80, Winter 1994.

ROSS, S. A.

Options and efficiency. Quarterly Journal of Economics, v. 90, n. 1, p. 75-90, 1976.

SHIMKO, D. C.

Finance in continuous time: a primer. Miami: Kolb Publishing Company, 1992.

STRONG, R. A;

DICKINSON, A.

Forecasting better hedge ratios. Financial Analysts Journal, v. 50, n.1, p. 70-72, Jan./Feb. 1994.

WHALEY, R. E.

Valuation of American call options on dividend paying stocks. Journal of Financial Economics, v. 10, n. 1, p. 29-57, Mar. 1982. 
APPENDIX 1

List of Stocks and Proportions Invested on the Simulated Stock Portfolios

\begin{tabular}{|c|c|c|c|c|}
\hline Ner & & Stocks & Pat 1 & Part 2 \\
\hline 1 & $\overline{A L D}$ & Allid Dameq & $0.40 \%$ & $1.25 \%$ \\
\hline 2 & AFT & $\mathrm{BAA}$ & $0.09 \%$ & $305 \%$ \\
\hline 3 & AMS & Brith Aingys & $8.00 \%$ & $836 \%$ \\
\hline 4 & AYL & Safenoy & - & - \\
\hline 5 & BHM & Smthritine Beechm & - & - \\
\hline 6 & BOT & Boots Co & $6.19 \%$ & $5.11 \%$ \\
\hline 7 & $\mathrm{BP}$ & Brith Petrokum & $3165 \%$ & $31.51 \%$ \\
\hline 8 & ESS & Buss & - & - \\
\hline 9 & CTD & Cortmules & - & - \\
\hline 10 & cuA & Cammaciluturn & $5.65 \%$ & $063 \%$ \\
\hline 11 & $C W$ & Cble \& Wress & $3.00 \%$ & $3.46 \%$ \\
\hline 12 & Gxo & Ghwo Welleme & - & - \\
\hline 13 & HSB & HSBC HHing & - & - \\
\hline 14 & $\mathrm{ICI}$ & Imperil Chemiralindxtris & $152 \%$ & $1.60 \%$ \\
\hline 15 & $\mathrm{KGF}$ & Krifikher & - & - \\
\hline 16 & IS & Lond Secritis & $9.20 \%$ & $767 \%$ \\
\hline 17 & $\mathrm{MS}$ & Marbs ard Spercer & $2.15 \%$ & - \\
\hline 18 & FWT & Natimal Westmiruter Brak & - & - \\
\hline 19 & RUT & Reuters Holings & - & - \\
\hline 20 & SAH & Saritury & - & - \\
\hline 21 & SHL & Shell Trapep \& Trativg Co & - & - \\
\hline 22 & STL & Eritin Steel & $0.40 \%$ & $003 \%$ \\
\hline 23 & STR & Starehoxe & $8.18 \%$ & $11.28 \%$ \\
\hline 24 & $T W$ & Themes Whater & $5.60 \%$ & $6.79 \%$ \\
\hline
\end{tabular}


ApPendix 2

\section{Resume of the Option Hedging Strategies Selected}

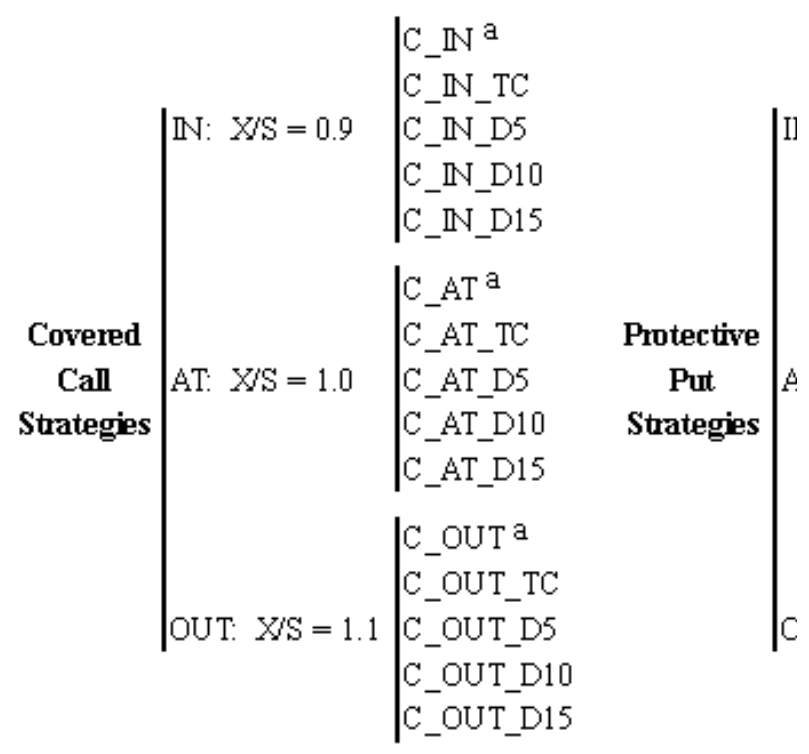

Notes: ${ }^{\mathrm{a}}$ = strateges wiflout trareaction costs (6). All other 24 strategies irchrle option hedging strategies for each stock 
ApPendix 3

Daily Returns from Option Delta Hedging Strategies Without Transaction Costs

Continuously Compounded Rate of Return

\begin{tabular}{|c|c|c|c|c|}
\hline \multirow[b]{2}{*}{ Patfolio 1} & \multicolumn{3}{|c|}{ Ktifh Cal Options } & \\
\hline & C_IN & C_AT & c_ouT & \\
\hline Aprerage & $0,0217 \%$ & $00261 \%$ & $0 \rho 289 \%$ & \\
\hline S.Dev. & $0,1210 \%$ & $0,2065 \%$ & $0.2660 \%$ & \\
\hline Kurtosi & 5,1796 & $4 \$ 190$ & 1,1682 & \\
\hline Sextress & $-0,2583$ & $-0,3549$ & $-0,3104$ & \\
\hline H.Obs. & 485 & 485 & 485 & \\
\hline Patfolio 2 & C_IN & C_AT & C_0UT & P. \\
\hline frorage & $0,0218 \%$ & $00264 \%$ & $0,302 \%$ & \\
\hline S.Dev. & $0,1264 \%$ & $0,2075 \%$ & $0,2709 \%$ & \\
\hline Kurtosi & $5 \oint 450$ & 47682 & 1,0512 & \\
\hline Senmess & $-0,2352$ & $-0,3001$ & $-0,2467$ & \\
\hline N.Obs. & 485 & 485 & 485 & \\
\hline Patfolio 3 & C_IN & C_AT & C_0UT & $\bar{P}$ \\
\hline Afrerage & $0,0219 \%$ & $00269 \%$ & $00319 \%$ & 0,0 \\
\hline S.Der. & $0,1322 \%$ & $0,2084 \%$ & $0,2713 \%$ & 0 \\
\hline Kurtosi & $5 \beta 129$ & 4,4655 & 0,8546 & \\
\hline Sermiess & $-0,2635$ & $-0,3350$ & $-0,1647$ & \\
\hline N.Obs. & 485 & 485 & 485 & \\
\hline Patfolio 4 & C_IN & C_AT & C_0UT & $\mathrm{p}$ \\
\hline Afrerase & $0,0220 \%$ & $0 \rho 249 \%$ & $0 \rho 270 \%$ & 0 , \\
\hline S.Der & $0,1098 \%$ & $0,1773 \%$ & $0.2295 \%$ & \\
\hline Kurtosis & 28619 & 45168 & 03223 & \\
\hline
\end{tabular}


ApPendix 4

Daily Returns from Option Delta Hedging Strategies Including Transaction Costs

Continuously Compounded Rate of Return

\begin{tabular}{|c|c|c|c|c|}
\hline \multirow[b]{2}{*}{ Patfolio 1} & \multicolumn{3}{|c|}{ Mtin Cal Optians } & \multirow[b]{2}{*}{ P_I } \\
\hline & C_IN_TC & C_AT_TC & C_OUT_TC & \\
\hline fterage & $-00086 \%$ & $-00244 \%$ & $-0,0369 \%$ & \\
\hline Dev. & $1384 \%$ & $2208 \%$ &, $259 \%$ & \\
\hline IItமsi & 38302 & 4,9038 & 13906 & \\
\hline ss & $-0,1747$ & $-0,3662$ & $-0,3140$ & \\
\hline N.0bs. & 485 & 485 & 485 & \\
\hline Patfolio 2 & C_IN_TC & C_AT_TC & C_OUT_TC & P_I \\
\hline fferage & $-0 \oint 087 \%$ & $-0 \emptyset 264 \%$ & $-0,0341 \%$ & - \\
\hline S.Dev. & $0,1410 \%$ & $0,2220 \%$ & $0,2971 \%$ & \\
\hline intosi & 39390 & 4,9010 & 1,2666 & \\
\hline Stew & $-0,1747$ & $-0,3066$ & -0.2601 & \\
\hline H.Obs. & 485 & 485 & 485 & \\
\hline Patfolio 3 & C_IH_TC & C_AT_TC & C_OUT_TC & $F_{-}$ \\
\hline terage & $-0 \rho 097 \%$ & $-0 \emptyset 27 \%$ & $-0,0326 \%$ & -0 \\
\hline & $0,1418 \%$ & $0,2243 \%$ & $0,2960 \%$ & \\
\hline Kuntosi & 4,3065 & 6034 & $1 \emptyset 907$ & \\
\hline Shempress & $-0,1804$ & $-0,3206$ & $-0,1819$ & \\
\hline F.Obs. & 485 & 485 & 485 & \\
\hline Patfolio 4 & C_IN_TC & C_AT_TC & C_OUT_TC & $\mathrm{P}_{-}$ \\
\hline ftrerage & $-00122 \%$ & $-0,0336 \%$ & $-0,0298 \%$ & - \\
\hline & $0,1156 \%$ & $0,1992 \%$ & $0,2351 \%$ & \\
\hline Kuntosi & 23764 & 1,9995 & 0,3548 & \\
\hline
\end{tabular}




\section{APPENDIX 5}

\section{Daily Returns from Option Delta Hedging Strategies "Discrete" Rebalancing Intervals - With Call Options}

Continuously Compounded Rate of Return

\begin{tabular}{|c|c|c|c|c|c|c|}
\hline \multirow[b]{2}{*}{ Font. 1} & \multicolumn{3}{|c|}{ IN the-Mong } & \multicolumn{3}{|c|}{ AT-the-Money } \\
\hline & C.파-DS & C.-IN-D10 & C- IN-D 15 & C.AT-DS & C- AT-D 10 & C.AT-D 15 \\
\hline ivera: & $-0,0038 \%$ & $0,0002 \%$ & $0,0070 \%$ & $-0,0080 \%$ & $0,0017 \%$ & $0,0114 \%$ \\
\hline SDer. & $0,1462 \%$ & $0,1537 \%$ & $0,1662 \%$ & $0,2352 \%$ & $0,2552 \%$ & $0,2702 \%$ \\
\hline Kurtosis & 3,6385 & 3,1733 & 2,3393 & 5,4690 & 5,0450 & 5,5484 \\
\hline Shentress & $-0,1334$ & $-0,1161$ & $-0,0768$ & $-0,6866$ & $-0,7645$ & $-0,7874$ \\
\hline N.Obs. & 485 & 485 & 485 & 485 & 485 & 485 \\
\hline Font. 2 & C.IN-DS & C-IN-D10 & C-IN-D 15 & C-AT-DS & C- $A \mathrm{~T}-\mathrm{D} 10$ & C-AT-D 15 \\
\hline Amera & $-0,0037 \%$ & $0,009 \%$ & $0,0062 \%$ & $-0,0104 \%$ & $0,0011 \%$ & $0,0113 \%$ \\
\hline SDeN. & $0,1497 \%$ & $0,1576 \%$ & $0,1737 \%$ & $0,2353 \%$ & $0,2523 \%$ & $0,2688 \%$ \\
\hline Kurtosis & 3,8321 & 3,7044 & 2,8722 & 5,6424 & 5,0142 & 5,0155 \\
\hline Sherrovess & $-0,1415$ & $-0,1366$ & $-0,1210$ & $-0,6540$ & $-0,6738$ & $-0,6151$ \\
\hline N.0bs. & 485 & 485 & 485 & 485 & 485 & 485 \\
\hline Fort. 3 & C-IN-D5 & C-IV-D10 & C-IN-D15 & C-AT-DS & C-AT-D 10 & C-AT-D15 \\
\hline imथே & $-0,0036 \%$ & $0,003 \%$ & $0,0066 \%$ & $-0,0127 \%$ & $0,0001 \%$ & $0,0115 \%$ \\
\hline SDet. & $0,1501 \%$ & $0,1564 \%$ & $0,1737 \%$ & $0,2366 \%$ & $0,2556 \%$ & $0,2720 \%$ \\
\hline Kurtosis & 4,3541 & 4,2803 & 3,3676 & 5,6540 & 5,0603 & 5,0546 \\
\hline Shentress & $-0,1256$ & $-0,1128$ & $-0,0948$ & $-0,6835$ & $-0,6604$ & $-0,0319$ \\
\hline N.Obs. & 485 & 485 & 485 & 485 & 485 & 485 \\
\hline Fort. 4 & C.IN-DS & C-IN-D10 & C-IN-D 15 & C-AT-DS & C- $A \mathrm{~T}-\mathrm{D} 10$ & C-AT-D 15 \\
\hline iverag & $-0,0051 \%$ & $0,0012 \%$ & $0,0071 \%$ & $-0,0169 \%$ & $-0,0014 \%$ & $0,0095 \%$ \\
\hline SDeU. & $0,1222 \%$ & $0,1268 \%$ & $0,1356 \%$ & $0,2144 \%$ & $0,2319 \%$ & $0,2459 \%$ \\
\hline Kurtosis & 1,9588 & 1,7360 & 1,6472 & 19164 & 2,4136 & 3,3155 \\
\hline Shentress & $-0,1554$ & $-0,0554$ & $-0,0657$ & $-0,6522$ & $-0,6668$ & $-0,8105$ \\
\hline N.Obs. & 485 & 485 & 485 & 485 & 485 & 485 \\
\hline Font. 5 & C-IN-DS & C-IV-D10 & C-IN-D15 & C-AT-DS & C- $A T-D 10$ & C-AT-D15 \\
\hline Aт⿺rag & $-0,0050 \%$ & $0,0015 \%$ & $0,0067 \%$ & $-0,0272 \%$ & $-0,0009 \%$ & $0,0099 \%$ \\
\hline SDet. & $0,1316 \%$ & $0,1453 \%$ & $0,1504 \%$ & $0,2440 \%$ & $0,2715 \%$ & $0,3083 \%$ \\
\hline Kurtosis & 1,7371 & 1,0716 & 10006 & 3,4241 & 3,7864 & 4,9792 \\
\hline Shentress & $-0,2831$ & $-0,2260$ & $-0,3107$ & $-0,6694$ & $-0,7605$ & $-0,9398$ \\
\hline W.Obs. & 485 & 485 & 485 & 485 & 485 & 485 \\
\hline
\end{tabular}




\section{APPENDIX 6}

\section{Daily Returns from Option Delta Hedging Strategies "Discrete" Rebalancing Intervals - With Put Options}

Continuously Compounded Rate of Return

\begin{tabular}{|c|c|c|c|c|c|c|}
\hline \multirow[b]{2}{*}{ Purt. 1} & \multicolumn{3}{|c|}{ In-the-Money } & \multicolumn{3}{|c|}{ AT-the-Money } \\
\hline & P. IIN-D5 & P-IN-D10 & P-IN-D 15 & P-AT-DS & P.AT-D 10 & P-AT-D15 \\
\hline fterage & $-00037 \%$ & $-00003 \%$ & $0,0034 \%$ & $-00012 \%$ & $0,0024 \%$ & $00097 \%$ \\
\hline SDev. & $0,1860 \%$ & $0,1938 \%$ & $0,2038 \%$ & $0,3255 \%$ & $0,3411 \%$ & $0,3516 \%$ \\
\hline Kurtosis & 37968 & 3,5770 & 3,3120 & 29417 & 2,5475 & 2,3213 \\
\hline Sirnness & 0,3711 & 0,4602 & 0,5696 & 0,4168 & 0,4804 & 0,3661 \\
\hline N.Obs. & 485 & 485 & 485 & 485 & 485 & 485 \\
\hline Furt. 2 & P-IN-D 5 & P-IN-D10 & P-IN-D15 & P-AT-DS & P-AT-D10 & P-AT-D15 \\
\hline fferage & $-0,039 \%$ & $-09003 \%$ & $0,0037 \%$ & $-09013 \%$ & $0,0023 \%$ & $0009 \%$ \\
\hline SDer. & $0,190 \pi \%$ & $0,1994 \%$ & $0,2151 \%$ & $0,3253 \%$ & $0,3413 \%$ & $0,3528 \%$ \\
\hline Kirtosis & 39197 & 3,7078 & 4,1072 & 3,1819 & 27694 & 2,6974 \\
\hline Sterniess & 0,4328 & 0,5053 & 0,7852 & 0,4071 & 0,4756 & 0,4008 \\
\hline N.Obs. & 485 & 485 & 485 & 485 & 485 & 485 \\
\hline Fint. 3 & P-IN-DS & P-Ir-D10 & P-IN-D15 & P-ÁT-DS & P-ÁT-D 10 & P-AT-D15 \\
\hline Ateris: & $-0 \rho 03 \%$ & $-0 p 001 \%$ & $0,0041 \%$ & $-0 \rho 012 \%$ & $0,0023 \%$ & $0 \rho 100 \%$ \\
\hline SDev. & $0,1934 \%$ & $0,2028 \%$ & $0,2193 \%$ & $0,3282 \%$ & $0,3444 \%$ & $0,3534 \%$ \\
\hline Kyrtosis & 37909 & 3,5827 & 38689 & 3,2984 & 28659 & 2,8245 \\
\hline Sterniess & 0,4440 & 0,5031 & 07717 & 0,3346 & 0,4206 & 0,3352 \\
\hline N.Obs. & 485 & 485 & 485 & 485 & 485 & 485 \\
\hline Furt. 4 & P. IN-D5 & P-IV-D10 & P-IN-D15 & P-AT-D5 & P.AT-D10 & P-AT-D15 \\
\hline Aterag & $-0 \rho 036 \%$ & $0 \rho 001 \%$ & $0,0038 \%$ & $-0 \rho 023 \%$ & $0,0013 \%$ & $0 \rho 092 \%$ \\
\hline SDev. & $0,1205 \%$ & $0,1285 \%$ & $0,1377 \%$ & $0,2460 \%$ & $0,2501 \%$ & $0,2707 \%$ \\
\hline Kurtosis & 2,5571 & 2,3215 & 2,2023 & 4,3572 & $4 \not 2683$ & 3,4197 \\
\hline Sterriess & $0 \rho 740$ & 0,2302 & 0,3870 & 0,7151 & 07719 & 0,6669 \\
\hline N.Obs. & 485 & 485 & 485 & 485 & 485 & 485 \\
\hline Part. 5 & P-IN-DS & P.IN-D10 & P-IN-D 15 & P-AT-DS & P.AT-D 10 & P-AT-D15 \\
\hline Aterag & $-0 \rho 049 \%$ & $-0 p 008 \%$ & $0,0040 \%$ & $-0 \rho 02 \pi \%$ & $0 \rho 011 \%$ & $0 \rho 06 \%$ \\
\hline SDev. & $0,1649 \%$ & $0,1755 \%$ & $0,1861 \%$ & $0,2598 \%$ & $0,2675 \%$ & $0,2824 \%$ \\
\hline Kurtosis & 39286 & 3,9853 & 4,4002 & $4 \not 009$ & $4 \$ 300$ & 6,1454 \\
\hline Sterniess & 0,009 & 0,8146 & 0,8856 & 06754 & 0,7728 & 1,0810 \\
\hline N.Obs. & 485 & 485 & 485 & 485 & 485 & 485 \\
\hline
\end{tabular}




\section{Appendix 7}

\section{F and Kruskal-Wallis Tests For Different Means by Strategy}

\begin{tabular}{|c|c|c|c|c|c|c|}
\hline Strutegied'Grous & Fstot & $p$ wo bo & d.f. & $F_{\mathrm{CT}^{5}}$ & $F_{\text {(Tit }}{ }^{150}$ & Hetut \\
\hline \multicolumn{7}{|c|}{ 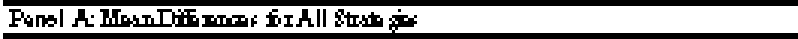 } \\
\hline Cst and Put & 156,65 & $0,00 \%$ & $29,1+490$ & 1,47 & $1, \bar{\pi}$ & $589, \pi 3$ \\
\hline cols & щ,81 & $0,00 \%$ & $14: 7245$ & 1,69 & 2,08 & 354,83 \\
\hline Pot & 107,20 & $0,00 \%$ & $14 ; \pi 45$ & 1,69 & 1,08 & 334,19 \\
\hline \multicolumn{7}{|c|}{ 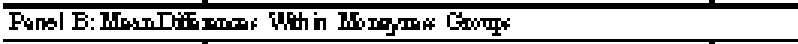 } \\
\hline \multicolumn{7}{|l|}{ ¿ lt } \\
\hline Atter Morry & 79,05 & $0,00 \%$ & $4,2+15$ & 1,38 & 3,33 & 110,90 \\
\hline Irr the-Mom & $43, \pi$ & $0,00 \%$ & 4,2415 & 1,38 & 3,33 & 102,17 \\
\hline Qutoftermorgy & $\pi, 74$ & $0,00 \%$ & 4,2415 & 1,38 & 3,33 & 110,6 \\
\hline \multicolumn{7}{|l|}{ Futs } \\
\hline Atter $\mathrm{Mom}=\mathrm{Y}$ & $\$ 8,16$ & $0,00 \%$ & 4,2415 & 2,38 & 3,33 & 104,43 \\
\hline Irrete- $\mathrm{Mom} Y$ & $5+39$ & $0,00 \%$ & 4,1415 & 1,38 & 3,33 & 102,63 \\
\hline Dutof ther Morgy & 75,16 & $0,00 \%$ & $4,2+15$ & 1,38 & 3,33 & 124,12 \\
\hline \multicolumn{7}{|c|}{ 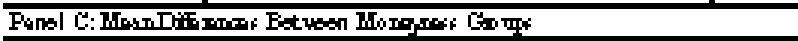 } \\
\hline Cal and Fu & 37,05 & $0,00 \%$ & $5 ; 2 \% 8$ & 2,12 & 3,01 & 5786 \\
\hline cols & $n, 45$ & $0,00 \%$ & $2 ; 14+9$ & 3,00 & 4,62 & 2988 \\
\hline P䒠 & 31,33 & $0,00 \%$ & $2 ; 14+9$ & 3,00 & 4,62 & 39,60 \\
\hline \multicolumn{7}{|c|}{ 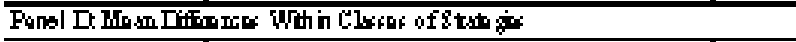 } \\
\hline \multicolumn{7}{|l|}{ 1.Colt and Frt } \\
\hline 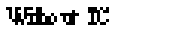 & 48,00 & $0,00 \%$ & $5 ; 1696$ & 2,12 & 3,02 & 8759 \\
\hline $\mathrm{D} .5$ & 40,25 & $0,00 \%$ & $5 ; 2896$ & 2,12 & 3,02 & 107,36 \\
\hline mó & $11, \pi$ & $0,00 \%$ & $5 ; 2896$ & 1,12 & 3,02 & $\pi, \pi 0$ \\
\hline D5 & 7,21 & $0,00 \%$ & $5 ; 2896$ & 2,21 & 3,02 & 45,08 \\
\hline ICt & 5,91 & $0,00 \%$ & $5 ; 1896$ & 1,12 & 3,02 & 16,60 \\
\hline \multicolumn{7}{|l|}{ 2.4tt } \\
\hline 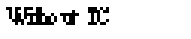 & 14,25 & $0,00 \%$ & $1 ; 149$ & 3,00 & 4,62 & 34,29 \\
\hline $\mathrm{Dls}$ & 7,86 & $0,00 \%$ & $1 ; 149$ & 3,00 & 4,62 & 47,62 \\
\hline Dó & 10,28 & $0,00 \%$ & $2 ; 1449$ & 3,00 & 4,62 & $21, \pi$ \\
\hline D5 & 6,01 & $0,25 \%$ & $2 ; 149$ & 3,00 & 4,62 & 16,34 \\
\hline IC & $4, \pi$ & $0,90 \%$ & $2 ; 1449$ & 3,00 & 4,62 & 11,29 \\
\hline 3 Frts & & & & & & \\
\hline
\end{tabular}




\section{APPENDIX 8}

\section{F and Kruskal-Wallis Tests For Different Means by Portfolio}

\begin{tabular}{|c|c|c|c|c|c|c|}
\hline Strategies/Grouss & F-stat & $\mathrm{p}$ value & d.f. & $\mathrm{F}_{\mathrm{crit}^{5}}{ }^{5}$ & $\mathrm{~F}_{\mathrm{crit}^{1}}{ }^{1 \%}$ & H-stat \\
\hline \multicolumn{7}{|c|}{ Panel A Portfolio Mean Differences for All Strategies } \\
\hline Calls and Puts & 4,29 & $1,38 \%$ & $4 ; 2415$ & 2,38 & 3,33 & 10,62 \\
\hline Calls & 1,27 & $27,97 \%$ & $4 ; 2415$ & 2,38 & 3,33 & 4,65 \\
\hline Puts & 1,07 & $34,23 \%$ & $4 ; 2415$ & 2,38 & 3,33 & 3,72 \\
\hline \multicolumn{7}{|c|}{ Panel B: Portfolio Mean Differences for Call Moneyness Groups } \\
\hline At-the-Money & 1,20 & $30,27 \%$ & $4 ; 2415$ & 2,38 & 3,33 & 3,06 \\
\hline In-the-Money & 1,06 & $34,52 \%$ & $4 ; 2415$ & 2,38 & 3,33 & 4,46 \\
\hline Out- of-the-Money & 0,69 & $50,03 \%$ & $4 ; 2415$ & 2,38 & 3,33 & 3,65 \\
\hline \multicolumn{7}{|c|}{ Panel C: Portfolio Mean Differences for Put Moneyness Groups } \\
\hline At-the-Money & 0,09 & $91,45 \%$ & $4 ; 2415$ & 2,38 & 3,33 & 1,97 \\
\hline In-the-Money & 0,79 & $45,33 \%$ & $4 ; 2415$ & 2,38 & 3,33 & 2,55 \\
\hline Out- of-the-Money & 1,18 & $30,72 \%$ & $4 ; 2415$ & 2,38 & 3,33 & 3,96 \\
\hline
\end{tabular}

